\title{
Laboratory station for research of the innovative dry method of exhaust gas desulfurization for an engine powered with residual fuel
}

Development of technology for exhaust gas desulfurization in marine engines using the dry method is, nowadays, a priority due to the calendar of introducing restrictions by the Directive of the European Parliament and of the Council 2012/33/EU of 21 November 2012. According to this directive, starting from 1 January 2015, inside the SECA (Sulphur Emission Control Area) the maximum sulfur content of marine fuels used on territorial seas is $0.1 \%$ per weight unit. But at the same time the directive allows for the use of exhaust gas desulfurization plant operating in a closed system. The ship equipped with the system will be able to use fuels with a high sulfur content, which will then be removed from the exhaust gas through an applied adsorber, and the reacted adsorbent is received by specialized services stationed in harbors. The International Maritime Organization has set a limit value of the emissions of sulfur oxides in exhaust gases of marine engines at $6 \mathrm{~g} / \mathrm{kWh}$ (International Convention for the Prevention of Sea Pollution from Ships MARPOL 73/78 Annex VI, Regulation 14).

Contemporary methods of exhaust gas desulfurization in marine engines are all expensive methods (4-5 million euro). This is, among other reasons, due to the limited market audience, but primarily due to the monop-olized position of manufacturers offering fabrication and assembly of this type of marine ship installations. Proposed as part of a research project financed by the Regional Fund for Environmental Protection and Maritime Economy in Gdansk, the dry method (adsorption) reducing SO $S_{x}$ emissions in exhaust gases of marine engines, is an alternative, and a definitely cheaper and therefore competitive solution, compared to the wet methods (absorption), which are currently the most widely used in marine scrubber installations. Importantly, as confirmed by the results of the study, the proposed dry method, in addition to the effective reduction of sulfur oxides, also reduces emissions of nitrogen oxides and carbon monoxide.

The paper presents the configuration and measurement capabilities of the test station built under the project, as well as the representative results of the investigations so far. During the exhaust gas desulfurization test a sodium adsorbent (sodium bicarbonate) and its modifications were used in the process of mechanical, chemical, and thermal activation. Two physicochemical processes were studied during the development of the method:

- of adsorbent's reaction on the chemical emission of the exhaust gas - the effectiveness of $\mathrm{SO}_{x}$ and $\mathrm{NO}_{x}$ compound removal, with various structural solutions in the process reactor,

- the impact of the adsorber on the emission source of sulfur oxides, that is, on the compression-ignition engine.

Therefore, one of the priorities of the project, with a utilitarian significance, was to determine the impact of the inclusion of the desulfurization installation in the exhaust gas system on the energy ratios of the engine.

Key words: compression-ignition engine, desulfurization of exhaust gas, dry method

\section{Introduction}

Maritime transport is an essential element of the functioning and development of many sectors of economy in the world. It plays a major role in international trade and the transport of people. Ships transport more than $2 / 3$ of the goods traded in the world. However, there exists the problem of air pollution caused by vessels that burn shipping fuel. High sulfur emissions originating from the combustion of heavy oil on watercraft contributes heavily to air pollution at sea and areas of port cities. This causes environmental damage in the form of acid rain and affects human health. As a result, the European Union is trying to fight the above issue by introducing new rules on the allowable limits for sulfur content in the fuel. It decrees the combustion of fuels with very low sulfur content, or alternatively, the use of exhaust gas desulfurization installations that meets the established requirements. EU, to meet this problem, issued a Directive of the European Parliament and of the Council 2012/33/EU of 21 November 2012, on sulfur content of fuels, which is the consequence of the International Convention for the Prevention of Pollution from Ships MARPOL 73/78 (Annex VI), signed and ratified by its Member States, where it was established that [7, 8]:
1. Inside the territory of SECA (Sulphur Emission Control Area), the maximum content of sulfur in shipping fuels used on the territorial seas is, as of January 1st, 2015, $0.1 \%$ per weight unit,

2. Outside of SECA territory, the maximum content of sulfur in shipping fuels is, as of January 1st, 2020, 0.5\% per weight unit.

Of course, the cited directive is an attempt to reduce the environmental damage in the form of acid rains and the impact on human health, resulted from the high emission of sulfur coming from the combustion of residual fuel on vessels, which is largely responsible for the air pollution at sea and areas of port cities. The effect of the directive seems to be incommensurate, as it does not drastically influence the countries situated around the North Sea as it does the ones around the Baltic Sea. Baltic Sea, according to the above legislation, is treated as an inland sea, which is a special SECA area. At the current price difference between fuels with low sulfurization and the heavy fuel oil, which is about $70-80 \%$ in favor of the heavy fuel, the usage of fuel with low sulfurization does not have an economic justification and it can conceivably lead to changing the sea trade routes to avoid the SECA territories [8]. 
Of course there exist alternative solutions to this problem. In accordance with the directive 2012/33/EU, there is a possibility of using a exhaust gas desulfurization installation in a closed system. The ship equipped with such an installation will be able to use fuels with a high sulfur content, which will then be removed from the exhaust by the applied absorber, and the generated reacting sorbent will be collected by specialized services located in harbors. Currently on the market there is equipment supplied with scrubbing installations, which absorb the pollution from a gas mixture. However, the cost of such an installation is very high, ranging between 4-5 million Euro. In addition, the use of scrubbers is also associated with significant operating costs connected to frequent exchanges of the sulfur absorbent agent, as well as, while using the wet method, the machinery needs to be equipped with complex water installations, which not only have a significant energy requirements, but also considerably reduce the cargo holding capacity of the ship, limiting its viability to large vessels only.

An alternative to the wet methods (absorption) of exhaust gas desulfurization are the dry methods (adsorption), which have found common use in power industry, in the combustion of solid fuels, and they are based on the chemical binding of $\mathrm{SO} 2$ in a system: polluted gas - solid (sorbent). In the dry method, the adsorbent is directly injected into the flue or the combustion chamber, where it reacts with the acidic byproducts of the process. In the case of marine uses, the dry desulfurization technology is being developed in a few European institutes, among which the most influential results have been achieved by the 2006 TEFLES project (Technologies and Scenarios for Low Emissions Shipping) [7]. As per the analysis of available sources, the leading role in this study, completed with pilot implementations on board, is held by COUPLE SYSTEMS $\mathrm{GmbH}$, which is a company that developed the original design of the installation marked DryEGCS (Dry Exhaust Gas Cleaning System) and the only one currently offering a product ready for installation on board of a ship [6]. In the presented solution, the desulfurization process is based on the chemisorption phenomenon, in which the adsorbent is a calcium hydroxide based substance, which, in a reaction with $\mathrm{SO} 2$, creates calcium sulfate (gypsum) and water. The used sorbent requires relatively high temperatures, which have a significant impact on the increase of sorptive capacity of calcium hydroxide.

In the solution proposed by the authors of the paper, sodium bicarbonate serves as the sorbent. The main advantage of using a sodium sorbent containing sodium bicarbonate is its exceptional sorption capacity to $\mathrm{SO} 2$ and other acidic pollutants of $\mathrm{HCl}$ and $\mathrm{HF}$ types, present in the gaseous products of fuel combustion. It also shows some capacity for removing nitric oxides, depending on the applied chemical modifiers. Sodium sorbents are characterized by their high reactivity in considerably lower temperatures (140 $\left.300^{\circ} \mathrm{C}\right)$ compared to other sorbents, e.g.: calcium $\left(800^{\circ} \mathrm{C}\right)$. It has a substantial impact on the ability to use sodium sorbents for the reduction of gas pollution in installations with a direct injection of sorbent into the exhaust gas stream of a low temperature. A very high reduction efficiency of gaseous pollutants by the sodium sorbent results in using a smaller amount of the adsorbent agent and of after-reaction waste, thus reducing costs for both the transport and processing of sorption products [5].

\section{The test station}

An alternative method for limiting the sulfur emission into the atmosphere, possible to use on marine ships, is the process of chemisorption using an agent binding this type of pollutants. The process of dry cleaning the gas exhaust emitted by the marine ship engines proposed by the authors does not require an advanced installation, as it does not provide for the circulation of streams, commonly used in the wet methods. Suggested sorbent, in form of a synthetically made sodium bicarbonate $\left(\mathrm{NaHCO}_{3}\right)$ has the ability to bind acidic pollutants present in the gaseous products of fuel combustion into salts which have an industrial application. During a thermal dissolution, carbon dioxide and water are released from it, as shown in the reaction:

$$
\mathrm{NaHCO}_{3} \rightarrow \mathrm{Na}_{2} \mathrm{CO}_{3}+\mathrm{H}_{2} \mathrm{O} \uparrow+\mathrm{CO}_{2} \uparrow
$$

Crude, as well as pure sodium bicarbonate are produced by Soda Polska Ciech company, in Inowrocław. Sodium bicarbonate (trade name), also called the sodium hydrogen carbonate or, colloquially, bicarb, is a white, dry, fine crystalline powder. The molecular weight of this product is 84.02 and its density at $20^{\circ} \mathrm{C}$ ranges from 2.16 to 2.22 $\mathrm{g} / \mathrm{cm}^{3}$

Increasing the activation of sodium bicarbonate is done by reducing the amount of water in its mass, which is achieved by drying in the temperature range of $50-60^{\circ} \mathrm{C}$. Within these temperatures, bicarb doesn't undergo a dissolution into sodium carbonate and water, while the reduction of mass is similar and related to an insignificant loss of ammonium compounds. Another way of activating sodium bicarbonate is the mechanical activation where the diameter of the powder grains is reduced, making its reactivity higher. Currently used is the grinding of sodium bicarbonate in various types of mills: impact, antijet or electromagnetic. Grinding the grains of the adsorbent results also in changes of the specific surface structure. Depending on the employed method of activation, the specific surface increases as much as tenfold in relation to the base value [5].

The created porous structure of the adsorbent grains has a large specific surface, located inside of the microstructures of the dissolved sodium carboxide, which is the result of reducing the molar volume of sodium bicarbonate. The creation of a large specific surface of an adsorbent contributes to increasing its sorption capacity and as such, the adsorption of a larger amount of $\mathrm{SO}_{2}$ from the waste gases.

Thus, while analyzing the sorption capacity of sodium bicarbonate it should be noted that it depends on the following:

- degree of dryness (water content),

- grammature of particles,

- specific surface of particles.

In addition to these factors, the contact time of the adsorbent with hot exhaust gases, that is the residence time of particles of sodium bicarbonate in the reactor chamber, seems equally as important. This time can be regulated depending on the method of feeding the adsorbent into the 
reactor chamber, by a right selection of the chamber height or through a choice of speed with which the exhaust flows through the reactor chamber.

While designing the test station it was decided that two methods of feeding the adsorbent will be used (Fig. 1):

- through atomization inside the chamber and its gravitational fall,

- through the application of a fluidized bed.

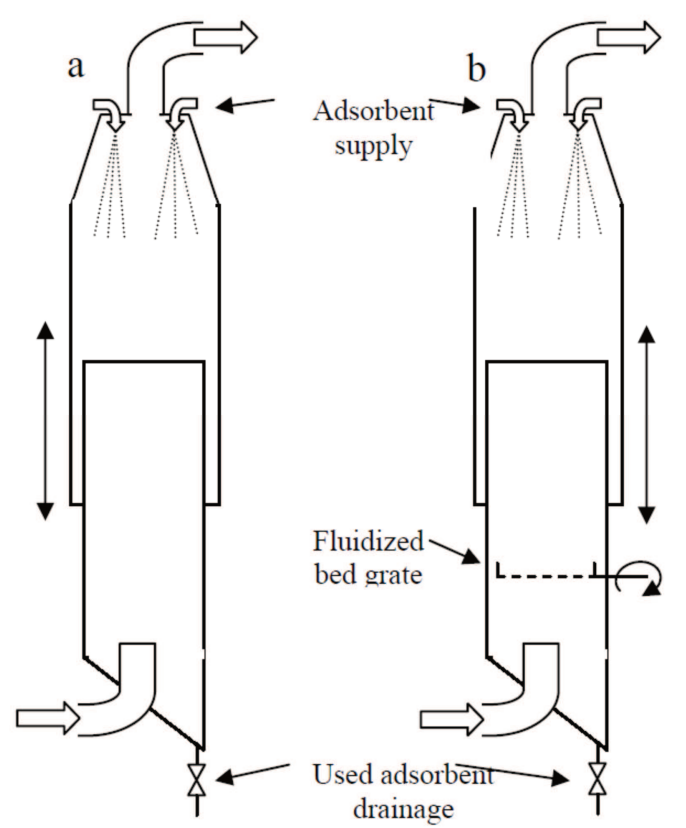

Fig. 1. The concept of the reactor structure: a) counter-current reactor, b) fluidized bed reactor

In the first case, while using the counter-current reactor, the time of the adsorbent's contact with the hot exhaust gases is essential for the optimal selection of the amount of the adsorbent being fed into the chamber. At the gravitational fall of the bicarbonate particles, except for their grammage (the diameter of the sodium bicarbonate particles ranges between 1 to $450 \mathrm{um}$, while the average diameter of these particles is around 140-150 um), an aerodynamic sedimentation will take place. This event will depend mainly on the specific surface of the adsorbent particles.

It can be assumed with a high probability that the nature of the fall, for both the gravitational and aerodynamic sedimentation, will proceed according to the normal schedule. The volatility of the aforementioned parameters of the adsorbent, that is, its grammage and the specific surface of its particles, is rather limited and as such the duration of the adsorbent's contact with the exhaust gases was decided to be regulated by lengthening of the path of its fall. For this reason, a double reactor blanket was suggested, which would allow a fluid increase of its length (height), and as such, lengthen the path and time of the fall of the adsorbent [1].

In case of using a reactor with a fluidized bed, it is essential to make the right selection of exhaust flow through the reactor, so that the conditions of a fluidized balance of adsorbent suspension would occur inside of the exhaust flow. Considering the limited capabilities for regulating the intensity of exhaust of the test engine, it was decided that a fan will be placed behind the reactor. Such placement is a result of the restrictions placed by the MARPOL convention and the ISO-8178 regulation [3, 4].

In accordance with these documents, it is prohibited to dilute fuel before the exhaust extraction point used for analyses.

For a correct conduct of a laboratory station, it is necessary to measure the following parameters:

- exhaust pressure before the reactor,

- exhaust pressure behind the reactor,

- exhaust pressure behind the filter,

- exhaust temperature inside of the exhaust manifold (behind the engine),

- exhaust temperature behind the exhaust heater,

- exhaust temperature behind the reactor,

- the concentration of toxic compounds inside of the exhaust manifold (behind the engine),

- the concentration of toxic compounds behind the reactor.

In addition to the above mentioned parameters, also realized is a measurement of the flow intensity of exhaust gas by measuring the volumetric air flow rate through the engine and measuring the volumetric fuel consumption.

Below is presented the measuring configuration of the laboratory station, which allows for the determining of emission values of basic exhaust components, in agreement with the ISO- 8178 regulation, based on the E-3 and D-2 tests, which are intended for marine ship engines used according to the full-load and propeller characteristics [8]. It is also possible to conduct research in the broad scope of input parameter changes, both during set work conditions and during transient states. The overview of the station is shown in Fig. 2.

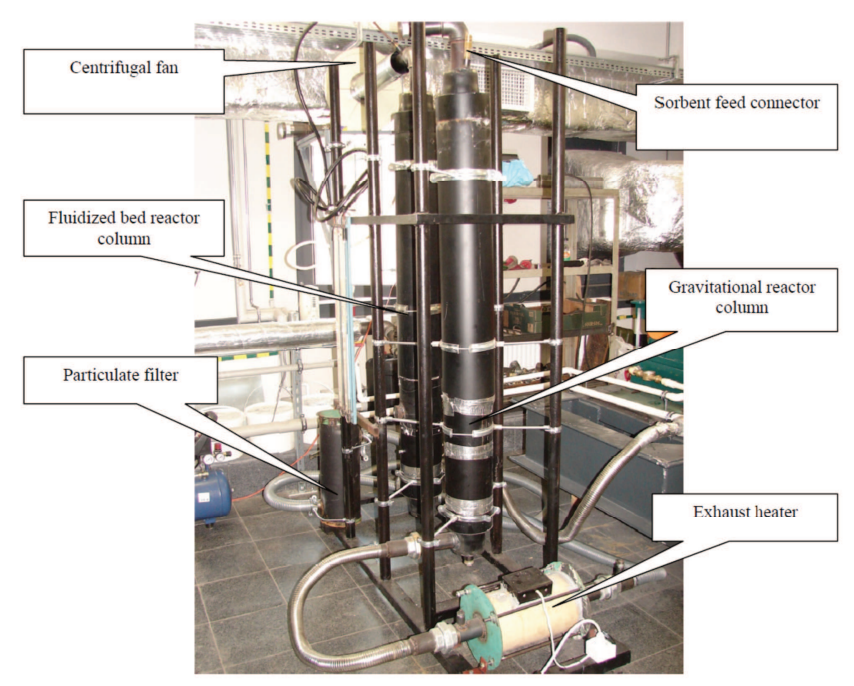

Fig. 2. An overview of the exhaust gas desulfurization station using the dry method

Considering the low power of the test engine powering the reactor (used was a single cylinder Farymann Diesel type $\mathrm{D}$, with power of $6.9 \mathrm{~kW}$ ), and therefore the small stream of exhaust and a high, compared to the employed engine, reactor volume, it was necessary to use an exhaust heater which would negate any heat loss. At first, the heat 
loss was significant and it lead to decreasing the dew point which, in turn, resulted in the hydration phenomenon, thus reducing the sulfur oxide concentration before it reached the reactor chamber and which intensified the low temperature corrosion processes. Of course, considering the goal of the research, it was essential to keep a relatively high concentration of $\mathrm{SO}_{2}$. Using the exhaust heater allowed the exhaust to stay at a temperature oscillating around $120^{\circ} \mathrm{C}$. Aside from the heater, it was decided that thermal isolation made out of mineral wool would be used, which resulted in raising the exhaust temperature by another $20^{\circ} \mathrm{C}$.

\section{Initial research using the dry method of exhaust desulfurization}

As mentioned before, the reactor station of the dry method of desulfurization cooperated with a single cylinder diesel engine Farymann type D, which was powered by fuel with an increased sulfur content.

The measurement of toxic compound concentration in the exhaust was conducted using an electrochemical exhaust analyzer KIGAZ 300 PRO made by Kimo company. In Figure 3, the placement of the sampling probe of the exhaust analyzer in the head of the reactor is shown [3, 4].

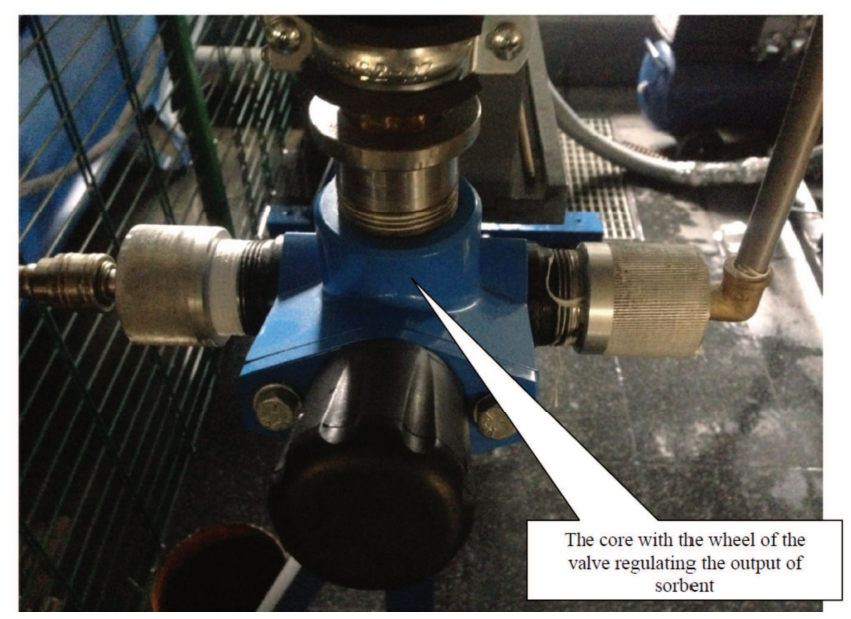

Fig. 3. A more detailed view of the head of the gravitational reactor

Research was conducted for two methods of feeding sorbent into the reactor:

- using a fixed bed with a limited fluidization phenomenon,

- through atomizing the sorbent inside of the reactor.

With the former method of feeding the reactor, a layer of around $10 \mathrm{~mm}$ of sorbent was laid on a grate installed inside of the reactor, which evenly covered the entire crosssection of the flue. This placement of sorbent forced a perpendicular flow of the exhaust stream through its layer. Considering the low speed of exhaust gases, the bed laid on the grate showed the qualities of a moving bed, characteristic of the initial stages of fluidized bed creation, when its surface undergoes loosening due to the passage of exhaust through it. After starting up the engine it was possible to note a brief, sudden increase in $\mathrm{SO}_{2}$ concentration, after which the sulfur oxide concentration held for around 10 seconds before decreasing again and stabilizing at around $40 \mathrm{ppm}$. Increasing the thickness of the sorbent layer to around $20 \mathrm{~mm}$ resulted in a similar course of events, i.e. after about 10 seconds from the concentration extreme caused by starting up the engine, a decrease took place equal to the error value of the measurement noise of the analyzer. This value is maintained for around two hours, after which it gradually rose along with the decrease of sorptive abilities of the sodium bicarbonate. Figure 4 shows the initial effect of the reducing action of the sorbent for a bed thickness of $10 \mathrm{~mm}$ (bed 1) and for a bed thickness of $20 \mathrm{~mm}$ (bed 2).

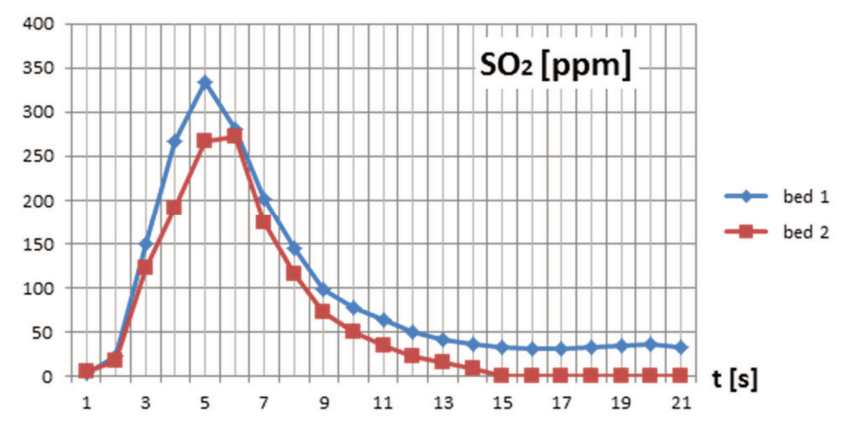

Fig. 4. Changes of sulfur dioxide concentrations while supplying the sorbent of a fixed bed

The latter method of feeding the sorbent was its atomization inside of the reactor chamber. In order to define the effectiveness of exhaust desulfurization using the dry method, an experiment was held for three settings of the valve controlling the output of the sorbent. Thus, the output of the sorbent was regulated by throttling the control valve at a set pressure (around 0.9 bar) of air supply. The degree of throttling was unambiguously defined through the measurement of the core height along with the wheel above the valve frame. Three settings were assumed, i.e.: $3 / 4,1 / 2$ and $1 / 4$ of a core valve stroke. Additionally, in order to define the degree of exhaust stream dilution by the air supply and thus its impact on concentration values of particular toxic compounds, including of course the impact on sulfur oxides, the reactor column was fed only with air supply for the $3 / 4$ stroke setting. The view of the valve is shown in Fig. 5 .

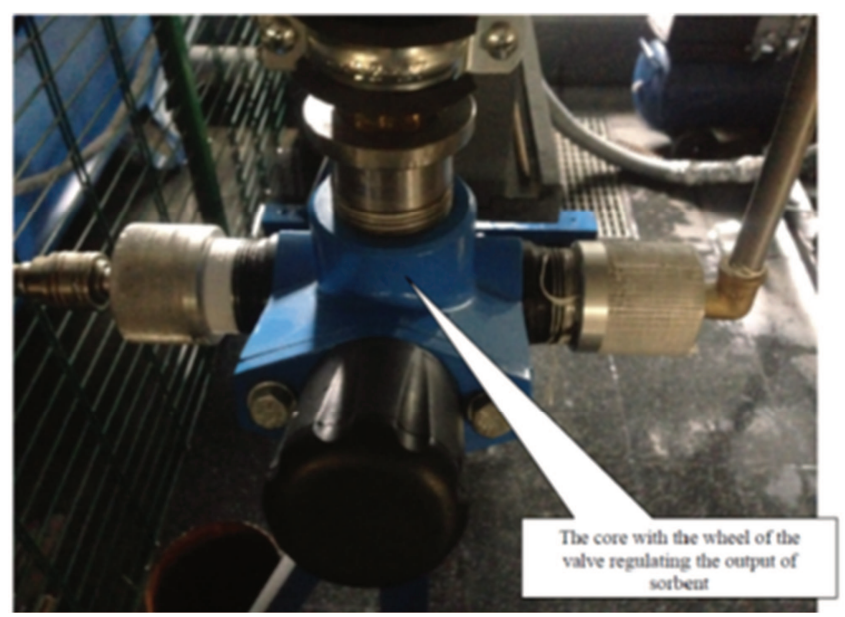

Fig. 5. View of the valve regulating the output of sorbent

The dilution degree is an essential value for at least two reasons. Firstly, as mentioned before, ISO-8178 regulation 
and the MARPOL convention prohibit the dilution of exhaust has before the point of their extraction for analysis. Secondly, the dilution of exhaust with air supply can yield apparent indications, which lead to faulty conclusions. Analysis results are presented in Fig. 6.

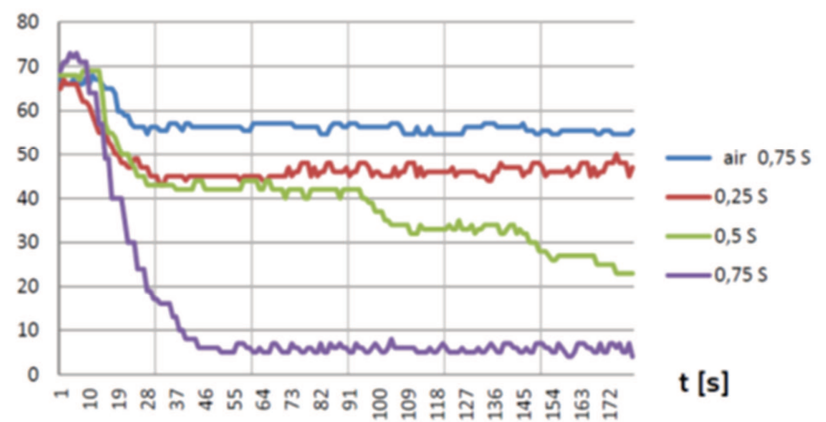

Fig. 6. Changes in concentrations of sulfur oxide with sorbent supply, where: $0.025 \mathrm{~S} ; 0.5 \mathrm{~S} ; 0.75 \mathrm{~S}$ - degree of opening of the control valve; air $0.75 \mathrm{~S}-$ air supply to the reactor at an opening of 0.75 valve stroke

In the case of sulfur oxide $\mathrm{SO}_{2}$, the impact of exhaust stream dilution is not as sizeable, however, it is still vital and cannot be ignored (Fig. 6). After around 15 seconds of feeding air supply into the reactor column, a significant decrease in $\mathrm{SO}_{2}$ concentration can be noticed.

The intensity of lowering the concentration, in comparison to the initial stage of the research is paradoxically higher (in an analogous example, concentration stabilization time was longer and amounted to around 15 seconds). After about another 10 seconds, concentration of $\mathrm{SO}_{2}$ stabilizes and maintains level. At a valve throttle of $3 / 4$ of core stroke, lowering the concentration equals about 8-10 ppm, which comes to, respectively, $12-15 \%$ of the base value. The reason for it may be the decreased volume of the reactor column (about 60\%), and at the same time the increased input of air supply into the exhaust stream going through the reactor.

It will also have an impact on the correct distribution of sorbent stream inside of the reactor column, and as such, its economic utilization. Currently the dose of sorbent is too high, which results in accumulation of unworked sorbent on the reactor walls, which in consequence changes the resistance of flow of the exhaust through the reactor, increasing the heat load of the engine. The influence of variable quantities of supplied sorbent on its reduction capacity are the most visible in case of $\mathrm{SO}_{2}$. It seems to be obvious as sodium bicarbonate serves mainly as sulfur oxide reduction agent.

While analyzing Fig. 6, it can be noted that along with the increase of sorbent stream (the measurement is the degree of the throttle on the control valve), its sorptive capacity also increases.

As such, in the case of a valve set to $1 / 4$ of its core stroke, the reduction capacity is, respectively, 35\%, and $68 \%$ for $1 / 2$ core stroke. In the case of a valve set to $3 / 4$ core stroke, the $\mathrm{SO}_{2}$ concentration inside of the reactor decreases to the level of the measurement noise error, i.e., the value of around 6-7 ppm. It constitutes almost $98 \%$ of the base value.
The changes of concentration of nitric oxide $\mathrm{NO}_{\mathrm{x}}$ (Fig. 7 ), with the reactor getting air supply are similar (decrease in $\mathrm{NO}_{\mathrm{x}}$ concentration by $15 \%$ ). It may signify that it also has the same dilution characteristics on an exhaust stream inside of a reactor. Observing the reduction effect of sodium bicarbonate on the concentration values of nitric oxides $\mathrm{NO}_{x}$ (Fig. 7) its valuable capacities can be noticed, even though they are not as impressive (it should be mentioned that for the purposes of the research, a sodium bicarbonate with heightened $\mathrm{NO}_{\mathrm{x}}$ sorptive capacity was used). The greatest sorptive capacity was observed for $3 / 4$ of core valve stroke, but very similar and comparable values were observed for the $1 / 4$ stroke and only slightly lower for the $1 / 2$ valve stroke. The sorptive effectiveness for nitric oxides amounted to around $22 \%$.

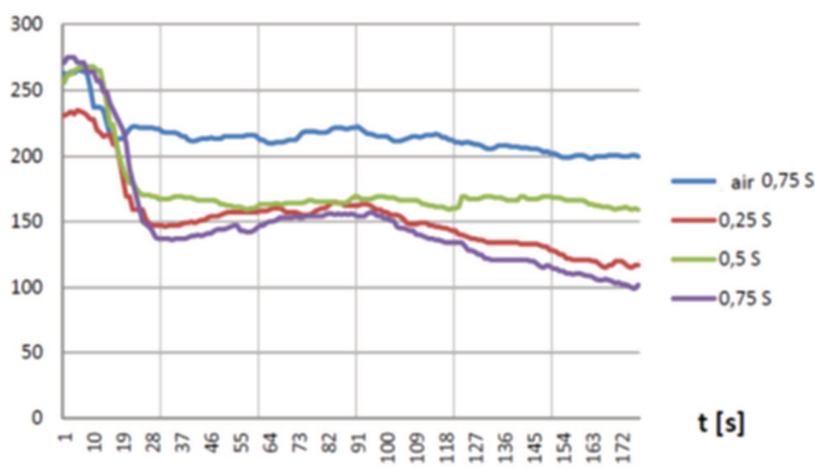

Fig. 7. Changes in concentrations of nitric oxides with a sorbent supply, where: $0,25 \mathrm{~S} ; 0,5 \mathrm{~S} ; 0,75 \mathrm{~S}$ - degree of opening of the control valve; air $0.75 \mathrm{~S}$ - air supply to the reactor at an opening of 0.75 valve stroke

Another issue that was analyzed during this research was the evaluation of sorptive effectiveness of the bicarbonate injected into the reactor. It was possible through determining the reaction time of the sorbent on the changes in $\mathrm{SO}_{2}$ concentration. Tests were conducted three times and they resulted in a relatively significant repeatability. Slight differences of sulfur oxide concentration values and time it took the concentration to stabilize are most likely caused by the minimal differences in the amount of injected sorbent. These differences could also be caused by errors in the valve adjustment for the control of sorbent input into the reactor. A comparison of these timings is shown in a graphic form in Fig. 8.

With conditions presented in Fig. 8a, the engine was loaded with $\mathrm{Ne}=0.9 \mathrm{~kW}$. The value of sulfur oxides before the sorbent injection oscillates around $40 \mathrm{ppm}$ while after its injection, the value decreases to around $14 \mathrm{ppm}$ in a comparable time which amounts to $30-40$ seconds, while for an engine load of $\mathrm{Ne}=2.0 \mathrm{~kW}$ (Fig. 8b), the initial values of concentrations are around 120-140 ppm for $\mathrm{SO}_{2}$ and decrease, after about 30 seconds, down to a value of 10-19 ppm.

Analyzing the changes of concentration values of $\mathrm{SO}_{2}$ it should be noted that the nature of these changes is similar. The differences are caused by the significantly, by almost triple, higher concentrations of $\mathrm{SO}_{2}$. This is because along with the shift of the load, the dosage of fuel increases while the $\mathrm{SO}_{\mathrm{x}}$ concentration in the exhaust gas depends almost 
solely on the amount of consumed fuel. An additional factor favorable to an increased sulfur oxide concentration is the increased combustion temperature, which also depends on the power load of the engine. a)

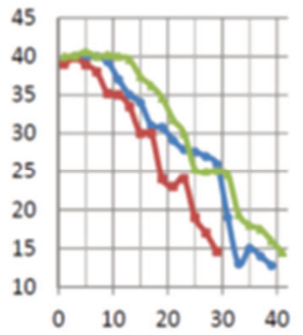

b)

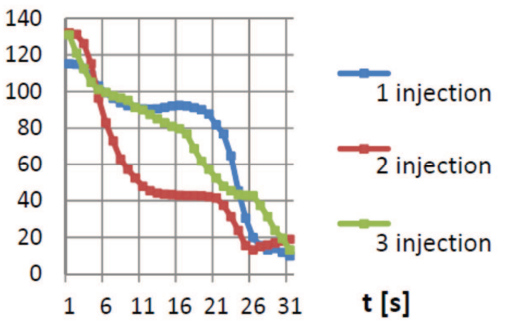

Fig. 8. Reaction time of the sorbent on $\mathrm{SO}_{2}$ concentration, where: a) $\mathrm{Ne}=$ $=0.9 \mathrm{~kW}, \mathrm{~b}) \mathrm{Ne}=2.0 \mathrm{~kW}$

As such it seems reasonable to come to the conclusion that the reactor capacity was largely oversized in relation to the size of the test engine used for powering the reactor.

\section{Summary}

Conducted research allowed for reaching the following conclusions:

1. The research confirmed the effectiveness of reduction impact of sodium bicarbonate as a sorbent for the reduction of oxides of not only sulfur, but also nitric oxides.

2. The suggested dry method is a competitive method relative to the wet methods used currently.

3. The research confirmed the validity of assumptions formulated during the creation of the laboratory station for testing the innovative dry method for the desulfurization of exhaust gas produced by a piston engine during the combustion of residual fuel.

4. The obtained results, on the level of quality reaction, are encouraging to conduct further research on the quantitative relations of a sorbent on the emission of reviewed sulfur, nitric and carbon oxides.

5. Encouraging is the perspective of research of dynamic reactions of bicarbonate sorbents on toxic compounds. Learning of the mechanisms of this phenomenon will allow the creation of a dynamic control of the sorbent output in case of the engine working during transient states. Such ability is not available to the wet method installations.

In order to continue with the research, it seems to be imperative to:

1. Conduct extensive optimization research, which would aim to help select the adequate amount of sorbent, necessary in the reduction of $\mathrm{SO}_{\mathrm{x}}$ and $\mathrm{NO}_{\mathrm{x}}$. For the control parameter of the sorbent stream, not only output of the control valve should be considered, but also the supply pressure and the structure of atomizers. It should allow the free shaping of the sorbent stream, depending on the needs.

2. In order to eliminate the dilution of exhaust which could appear in result of feeding the reactor with a solvent by means of compressed air injection, research should be conducted using a gas neutral to the process of cleaning the exhaust, e.g.: nitrogen $\mathrm{N}_{2}$ or carbon dioxide $\mathrm{CO}_{2}$.

\section{Bibliography}

[1] DZIUBIŃSKI, M., PRYWER, J. Mechanika płynów dwufazowych. 2009, WNT, Warszawa.

[2] KORCZEWSKI, Z., RUDNICKI, J., ZADRĄG, R. Budowa stanowiska laboratoryjnego do badania innowacyjnej metody suchej odsiarczania spalin silnika zasilanego paliwem pozostałościowym. Projekt dofinansowany ze środków Wojewódzkiego Funduszu Ochrony Środowiska i Gospodarki Wodnej (WFOŚiGW) w Gdańsku - sprawozdanie z realizacji zadania, Gdańsk 2016.

[3] RUDNICKI, J., ZADRĄG, R. Problems of modelling toxic compounds emitted by a marine internal combustion engine for the evaluation of its structure parameters. Combustion Engines. 2015, 3, 432-441.
Zbigniew Korczewski, DSc., DEng. - Faculty of Ocean Engineering and Ship Technology at Gdansk University of Technology.

e-mail: zbikorcz@pg.gda.pl

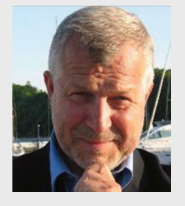

Ryszard Zadrąg, DEng. - Faculty of Ocean Engineering and Ship Technology at Gdansk University of Technology.

e-mail: ryszadra@pg.gda.pl
[4] RUDNICKI, J., ZADRĄG, R. Problems of modelling toxic compounds emitted by a marine internal combustion engine in unsteady states. Polish Maritime Research. 2014, 21, 57-65.

[5] SZYMANEK, A. Odsiarczanie spalin metodami suchymi, Europejski Fundusz Społeczny, Projekt „Plan Rozwoju Politechniki Częstochowskiej”, Częstochowa 2008.

[6] VESTERGAARD, O.G. Comparing wet and dry exhaust gas cleaning systems. Bachelor project. Aarhus School of Marine and Technical Engineering. Denmark 2013.

[7] WALTER, J., WAGNER, J. Choosing exhaust scrubber system. Flensburg University of Applied Sciences, 2012.

[8] ZADRĄG, R., KNIAZIEWICZ, T. Identification of diagnostic parameter sensitivity during dynamic processes of a marine engine. Combustion Engines. 2015, 3, 1007-1014.

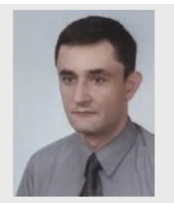

